\title{
Evidence based approach to the treatment of community-associated methicillin-resistant Staphylococcus aureus
}

REVIEW

This article was published in the following Dove Press journal:

Infection and Drug Resistance

2 June 2009

Number of times this article has been viewed

\author{
William J Peppard' \\ Anne Daniels' \\ Lynne Fehrenbacher ${ }^{2}$ \\ Jamie Winner ${ }^{3}$ \\ 'Froedtert Hospital Milwaukee, \\ Wisconsin, USA; ${ }^{2}$ Aurora St Luke's \\ Medical Center Milwaukee, Wisconsin, \\ USA; ${ }^{3}$ Clement J Zablocki VA Medical \\ Center, Milwaukee, Wisconsin, USA
}

Correspondence: William J Peppard Froedtert Hospital Pharmacy, 9200 West Wisconsin Avenue, Milwaukee, Wisconsin 53226 USA

$\mathrm{Tel}+\mathrm{I}(4 \mid 4)$ 805-6933

$\mathrm{Fax}+\mathrm{I}(4 \mid 4)$ 805-9283

Emailwpeppard@fmlh.edu
Abstract: Community-associated methicillin-resistant Staphylococcus aureus (CA-MRSA) infections have increased dramatically over the last two decades. The types of infections can range from complicated skin and skin structure infections (cSSSI) to pneumonia and endocarditis. Oral antimicrobial therapy, such as trimethoprim-sulfamethoxazole, clindamycin, long-acting tetracyclines, or linezolid may provide enhanced benefit to those with uncomplicated cutaneous lesions when used in conjunction with incision and drainage in an outpatient setting. However, resistance, susceptibilities, patient-specific circumstances, and adverse effects can impact a healthcare professional's choice of antibiotics. In patients with complicated infections requiring hospitalization or parenteral treatment, vancomycin remains the drug of choice, even though increased resistance and decreased efficacy have crept into clinical practice. Linezolid, quinupristin/dalfopristin, daptomycin, and tigecycline are alternative intravenous agents for the treatment of CA-MRSA. Investigational agents such as dalbavancin, telavancin, oritivancin, iclaprim, ceftobiprole, ceftaroline, and others may expand our therapeutic armamentarium for the treatment of infections caused by CA-MRSA in the future.

Keywords: community-associated methicillin-resistant Staphylococcus aureus, CA-MRSA, complicated skin and skin structure infections, cSSSI, Panton-Valentine leukocidin, PVL, in vitro activity

\section{Introduction}

Methicillin-resistant Staphylococcus aureus (MRSA) was first described in 1961 soon after the introduction of methicillin, the first beta-lactamase resistant penicillin. ${ }^{1}$ MRSA soon emerged as a common nosocomial organism infecting patients in hospitals and intensive care units around the world. ${ }^{2}$ Prior to the 1990s, MRSA was almost exclusively a nosocomial organism. During the 1990s, MRSA began to infect patients with no known contact to healthcare organizations and who were otherwise healthy. These types of MRSA were noted to be genetically unique and soon began to be referred to as community-associated MRSA (CA-MRSA). ${ }^{3}$ Understanding this complex pathogen has now become a primary focus for many practitioners as illness related to CA-MRSA can be life-threatening. Despite major medical advances, MRSA continues to cause significant disease.

\section{Epidemiology}

CA-MRSA differs from healthcare-associated MRSA (HA-MRSA) genetically and epidemiologically. Methicillin resistance is mediated by the mecA gene which resides on the staphylococcal cassette chromosome mec (SCCmec). SCCmec 
encodes for the penicillin-binding protein 2a (PBP2a) resulting in the inability of methicillin to bind to $S$. aureus. ${ }^{4}$ CA-MRSA strains predominantly carry SCCmec type IV; however, SCCmec type $\mathrm{V}$ has also been identified in these strains. ${ }^{3}$ These SCCmec genes are generally smaller than those genes found in HA-MRSA strains allowing for more rapid spread. In addition, these genes only confer resistance to methicillin and other beta-lactams while maintaining susceptibility to narrow-spectrum antibiotics such as tetracyclines, trimethoprim-sulfamethoxazole (TMP-SMX), and clindamycin. CA-MRSA, like HAMRSA, remains susceptible to vancomycin, linezolid, daptomycin, and quinupristin/dalfopristin (Q/D). ${ }^{3,5}$ One distinct feature of CA-MRSA is its ability to carry the gene encoding for Panton-Valentine leukocidin (PVL), a deadly exotoxin. This exotoxin is the key feature associated with CA-MRSA that causes necrotizing infections of the soft tissue as well as necrotizing pneumonias., ${ }^{2,6}$ CA-MRSA did not originate from the hospital setting. Rather, it appears as though methicillin-susceptible S. aureus (MSSA) acquired the SCCmec gene producing a new genetic variant with two distinct clones occurring in the United States, USA300 and USA400. USA300 more frequently contains PVL genes and is now considered a major cause of necrotizing soft tissue infections., ${ }^{2,3}$ The Centers for Disease Control and Prevention (CDC) define CA-MRSA infections as those seen in people who meet the following criteria: ${ }^{7}$

- Diagnosis of MRSA made in the outpatient setting or by a positive culture for MRSA within 48 hours of admission to the hospital.

- No medical history of MRSA infection or colonization.

- No medical history in the past year of:

- Hospitalization

- Admission to a nursing home, skilled nursing facility, or hospice

- Dialysis

- Surgery

- No permanent indwelling catheters or medical devices that pass through the skin into the body.

One important development with CA-MRSA is the observation of these strains among patients in the healthcare setting. Because most patients acquire CA-MRSA from the community and because these infections can be quite serious, many may require hospitalization which can potentially transmit these strains to other inpatients. ${ }^{8}$ A review of 352 patients within the same institution with HA-MRSA found that CA-MRSA had become the most common cause of HA-MRSA. When MRSA strains were phenotyped, it was noted that the SCCmec IV gene increased from $17 \%$ to $56 \%$ in a 5 -year period. ${ }^{9}$

\section{Clinical presentation and risk factors}

Skin and skin structures are the predominant sites of infection of CA-MRSA, furuncles being the most common type reported. CA-MRSA can also cause cellulitis, deep tissue abscesses, and in more serious cases, necrotizing fasciitis and osteomyelitis. CA-MRSA may be associated with localized necrosis caused by the PVL gene. Often, patients experience sudden onset of a raised red lesion with central necrosis resembling a spider bite. ${ }^{10}$ This can be confusing to both patients and physicians especially in areas of the United States where spider bites leading to cellulitis are uncommon. Presentations of this sort may be indicative of CA-MRSA infection as necrosis is a common feature of CA-MRSA both in skin and skin structure infections (SSSI) and lung infections. Pneumonia associated with PVL-producing CA-MRSA generally occurs as a necrotizing pneumonia with a high mortality rate. ${ }^{11}$ More cases of CA-MRSA necrotizing pneumonia have been seen in young, otherwise healthy children and adults. ${ }^{3}$ CA-MRSA necrotizing pneumonias are often seen following or concomitantly with an influenza-like illness. Patients often present with hemoptysis and a rapid onset of respiratory decompensation. In addition, patients appear septic with symptoms of hypotension, tachycardia, tachypnea, fever, and may often develop leukopenia. ${ }^{12}$

CA-MRSA has been reported to cause serious outbreaks of infections in certain populations including personnel in competitive team sports, Alaskan natives, Native Americans, correctional facility inmates, children, and military personnel. ${ }^{13}$ Transmission of CA-MRSA is predominantly through direct contact with an infected person. However, data from CA-MRSA outbreaks indicate that fomites, or inanimate objects, can also facilitate the spread of CA-MRSA. ${ }^{14}$ One notable incident occurred in 2003 when 8 MRSA infections developed in 5 professional football players. The MRSA clone was identified as a PVL-containing CA-MRSA which appeared to have been transmitted via close contact with infected abrasions and equipment. ${ }^{15}$

Risk factors for the acquisition of CA-MRSA are difficult to identify. It seems evident that close physical contact plays an important role; however, beyond that there are few well-designed studies that analyze risk factors. ${ }^{16}$ Risk factors that most healthcare professionals agree on are listed in Table $1.2,3,16,17$ 
Table I Risk factors for infection with community-associated

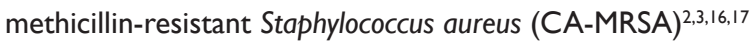

Children $<2$ years old

Children attending daycare centers

Injection drug users

Military personnel

Inmates

Homeless persons

Those in crowded living conditions

Household contact with a person known to be colonized and/or infected with MRSA

Men who have sex with men

HIV-infected persons

Athletes of contact sports

Adults $\geq 65$ years old

Poor personal hygiene

History of colonization or recent infection with CA-MRSA

Recent influenza-like illness or pneumonia

African Americans

Pacific Islanders

Native Americans

\section{In vitro activity}

The assessment of in vitro activity of a given compound against select clinically significant pathogens has always been an early component in the development of new antimicrobials. Once the in vitro activity has been well defined, additional drug-specific data follow including basic pharmacokinetic parameters, human safety data, and ultimately, human outcome data. Specific to $S$. aureus, and more specifically MRSA, the differentiation into CA-MRSA and HA-MRSA subsets is a relatively new concept. Consequently, in vitro data for MRSA is not often subdivided into CA-MRSA or HA-MRSA. For the assessment of in vitro activity of various drugs against CA-MRSA, data are currently limited but accumulating. While it is unclear whether the genotypic identification of a given strain is clinically significant once susceptibility testing has been performed, it is clear that the susceptibility patterns differ based on the origin of the strain.

Use of the term CA-MRSA with regard to in vitro susceptibilities in contemporary literature generally refers to one of two issues. First, it may refer to strains which are consistent with the CDC definition as previously described. ${ }^{7}$ Alternatively, the strain may have been genotyped and specifically identified to be a community-associated strain (ie, USA300, USA400, etc). For the purpose of this review, either determination has been considered sufficient to access in vitro activity. The in vitro activities of several antimicrobial agents have been evaluated against CA-MRSA and are summarized in Table 2. Included in this table are enteral and parenteral agents, both traditional and contemporary, which are commonly associated in the treatment of CA-MRSA infections.

\section{Treatment options}

Current guidelines recommend incision and drainage of uncomplicated-SSSI caused by CA-MRSA. ${ }^{18}$ Many patients can be treated with surgical drainage; however, antimicrobial therapy may provide additional benefits to the patient. ${ }^{19}$ Factors that may persuade a clinician to incorporate antimicrobial therapy into the treatment plan include: presence of cellulitis, swift enhancement of the SSSI, systemic illness, immunocompromised patient, age of the patient, abscess location that is difficult to access, and inappropriate response to the initial incision and drainage. ${ }^{20}$ Multiple non-beta-lactam oral antibiotics are available for outpatient therapy including: TMP-SMX, clindamycin, long-acting tetracyclines, and linezolid.

\section{Enteral treatment options Trimethoprim-sulfamethoxazole (TMP-SMX)}

TMP-SMX (Septra ${ }^{\circledR}$; King Pharmaceuticals, Bristol, TN, USA) is not approved by the Food and Drug Administration (FDA) for the treatment of staphylococcal infections. ${ }^{21}$ However, TMP-SMX has shown in vitro bactericidal properties against strains of CA-MRSA. ${ }^{22}$ The evidence to support the efficacy of TMP-SMX came from a randomized, controlled clinical trial comparing it with vancomycin in intravenous drug abusers with various $S$. aureus infections, including bacteremia, endocarditis, osteomyelitis, and SSSI. Vancomycin demonstrated superiority in the $S$. aureus treatment arm; however, the authors concluded that TMP-SMX is a viable treatment option in select cases of MRSA..$^{23}$ In another study conducted in an ambulatory clinic, the increased use of TMP-SMX correlated with improved clinical outcomes in patients with SSSI. ${ }^{24}$ While data are lacking, TMP-SMX is widely used in clinical practice.

\section{Clindamycin}

Clindamycin (Cleocin ${ }^{\circledR}$; Pfizer, Inc, New York, NY, USA) is another common antibiotic used to treat CA-MRSA. ${ }^{25}$ It has a potential protective effect against toxins, including the PVL toxin. ${ }^{26}$ There is a potential for resistance with high-inoculum infections via efflux or ribosomal alterations. A disk diffusion antibiotic assay (D-test) identifies inducible clindamycin 
Table 2 In vitro activity of select antimicrobial agents against community-associated methicillin-resistant Staphylococcus aureus (CA-MRSA)

\begin{tabular}{|c|c|c|c|c|c|c|}
\hline \multirow[b]{2}{*}{ Antimicrobial agent } & \multicolumn{6}{|c|}{ CA-MRSA } \\
\hline & $\begin{array}{l}\text { No. of } \\
\text { isolates }\end{array}$ & \% susceptible & $\begin{array}{l}\mathrm{MIC}_{50} \\
(\mu \mathrm{g} / \mathrm{mL})\end{array}$ & $\begin{array}{l}\text { MIC }_{90} \\
(\mu \mathrm{g} / \mathrm{mL})\end{array}$ & $\begin{array}{l}\text { MIC range } \\
(\mu \mathrm{g} / \mathrm{mL})\end{array}$ & Reference \\
\hline \multirow[t]{9}{*}{ Clindamycin } & 152 & 100 & $\leq 0.25$ & $\leq 0.25$ & $\leq 0.25$ & Sader et al $2008^{76}$ \\
\hline & 157 & 97 & na & na & na & King et al $2006^{89}$ \\
\hline & 127 & 96 & na & na & na & Huang et al $2006^{88}$ \\
\hline & 348 & 93 & na & na & na & Naimi et al $200 I^{90}$ \\
\hline & 200 & 92 & 0.25 & 0.5 & 0.03 to $>32$ & Tsuji et al $2007^{91}$ \\
\hline & 23 & 91 & na & 0.13 & $0.06-64$ & Johnson et al $2006^{49}$ \\
\hline & $130 \mid$ & 87 & na & na & na & Fridkin et al $2005^{87}$ \\
\hline & 191 & 80.6 & na & na & na & Crum et al $2006^{86}$ \\
\hline & 1989 & 34.2 & $>8$ & $>8$ & $\leq 0.06$ to $>8$ & Mendes et al $2008^{45}$ \\
\hline \multirow[t]{4}{*}{ Daptomycin } & 23 & 100 & na & 0.25 & $0.12-0.25$ & Johnson et al $2006^{49}$ \\
\hline & 60 & 100 & 0.25 & 0.25 & $0.12-0.5$ & Saravolatz et al $2007^{44}$ \\
\hline & 152 & 100 & 0.25 & 0.5 & $0.25-1$ & Sader et al $2008^{76}$ \\
\hline & 200 & 100 & 0.5 & I & $0.13-2$ & Tsuji et al $2007^{91}$ \\
\hline \multirow[t]{9}{*}{ Erythromycin } & 318 & 64 & na & na & na & Naimi et al $2001^{90}$ \\
\hline & 185 & 20 & na & na & na & Crum et al $2006^{86}$ \\
\hline & 1236 & 18 & na & na & na & Fridkin et al $2005^{87}$ \\
\hline & 157 & 13 & na & na & na & King et al $2006^{89}$ \\
\hline & 127 & 7 & na & na & na & Huang et al $2006^{88}$ \\
\hline & 1989 & 5.7 & $>8$ & $>8$ & $\leq 0.06$ to $>8$ & Mendes et al $2008^{45}$ \\
\hline & 200 & 4 & $>16$ & $>16$ & 0.13 to $>16$ & Tsuji et al $2007^{91}$ \\
\hline & 152 & 1.3 & $>8$ & $>8$ & 2 to $>8$ & Sader et al $2008^{76}$ \\
\hline & 23 & 0 & na & 64 & $2.0-64$ & Johnson et al $2006^{49}$ \\
\hline \multicolumn{7}{|l|}{ Fluoroquinolones } \\
\hline \multirow[t]{5}{*}{ Ciprofloxacin } & 325 & 93 & na & na & na & Naimi et al $2001^{90}$ \\
\hline & 23 & 83 & na & 16 & $0.12-64$ & Johnson et al $2006^{49}$ \\
\hline & 861 & 65 & na & na & na & Fridkin et al $2005^{87}$ \\
\hline & 127 & 53 & na & na & na & Huang et al $2006^{88}$ \\
\hline & 1989 & 15.1 & $>4$ & $>4$ & $\leq 0.03$ to $>4$ & Mendes et al $2008^{45}$ \\
\hline \multirow[t]{5}{*}{ Levofloxacin } & 152 & 92.8 & 0.25 & 0.5 & $\leq 0.12$ to $>4$ & Sader et al $2008^{76}$ \\
\hline & 157 & 90 & na & na & na & King et al $2006^{89}$ \\
\hline & 23 & 87 & na & 4 & $0.06-32$ & Johnson et al $2006^{49}$ \\
\hline & 1989 & 15.5 & $>4$ & $>4$ & 0.06 to $>4$ & Mendes et al $2008^{45}$ \\
\hline & 200 & 12 & $>16$ & $>16$ & 0.125 to $>16$ & Tsuji et al $2007^{91}$ \\
\hline Moxifloxacin & 23 & 96 & na & 1 & $0.03-4$ & Johnson et al $2006^{49}$ \\
\hline \multirow[t]{6}{*}{ Linezolid } & 23 & 100 & na & 2 & $2.0-2.0$ & Johnson et al $2006^{49}$ \\
\hline & 200 & 100 & 2 & 4 & $0.24-4$ & Tsuji et al $2007^{91}$ \\
\hline & 60 & 100 & 2 & 2 & 2 & Saravolatz et al $2007^{44}$ \\
\hline & 152 & 100 & 2 & 2 & $\mathrm{I}-2.0$ & Sader et al $2008^{76}$ \\
\hline & 1989 & $>99.9$ & 2 & 2 & $\leq 0.06-16$ & Mendes et al $2008^{45}$ \\
\hline & 25 & 96 & na & na & na & Fridkin et al $2005^{87}$ \\
\hline \multirow[t]{2}{*}{ Quinupristin-dalfopristin } & 60 & 100 & 0.25 & 0.5 & $0.25-1$ & Saravolatz et al $2007^{44}$ \\
\hline & 1989 & $>99.9$ & 0.5 & I & $\leq 0.25-2$ & Mendes et al $2008^{45}$ \\
\hline \multirow[t]{2}{*}{ Rifampin } & 23 & 100 & na & 0.03 & $0.03-0.03$ & Johnson et al $2006^{49}$ \\
\hline & 127 & 100 & na & na & na & Huang et al $2006^{88}$ \\
\hline
\end{tabular}

(Continued) 
Table 2 (Continued)

\begin{tabular}{|c|c|c|c|c|c|c|}
\hline & 157 & 99 & na & na & na & King et al $2006^{89}$ \\
\hline & 211 & 99 & na & na & na & Naimi et al $\left.200\right|^{90}$ \\
\hline & 887 & 98 & na & na & na & Fridkin et al $2005^{87}$ \\
\hline & 1989 & 93.7 & $\leq 0.5$ & $\leq 0.5$ & $\leq 0.5->2$ & Mendes et al $2008^{45}$ \\
\hline \multicolumn{7}{|l|}{ Tetracyclines } \\
\hline Doxycycline & 200 & 86 & 0.5 & 8 & $0.06->16$ & Tsuji et al $2007^{91}$ \\
\hline Minocycline & 166 & 100 & na & na & na & Crum et al $2006^{86}$ \\
\hline \multirow[t]{6}{*}{ Tetracycline } & 249 & 95 & na & na & na & Naimi et al $2001^{90}$ \\
\hline & 152 & 94.7 & $\leq 0.5$ & $\leq 0.5$ & $\leq 0.5->16$ & Sader et al $2008^{76}$ \\
\hline & 23 & 91 & na & 0.5 & $0.13-32$ & Johnson et al $2006^{49}$ \\
\hline & 1063 & 88 & na & na & na & Fridkin et al $2005^{87}$ \\
\hline & 127 & 80 & na & na & na & Huang et al $2006^{88}$ \\
\hline & 1989 & 9.1 & $\leq 2$ & 4 & $\leq 2->8$ & Mendes et al $2008^{45}$ \\
\hline \multirow[t]{2}{*}{ Tigecycline } & 76 & 100 & na & na & na & McAlesse et al $2005^{60}$ \\
\hline & 1989 & $98.2-100$ & $\leq 0.12$ & 0.5 & $\leq 0.12-0.5$ & Mendes et al $2008^{45}$ \\
\hline \multirow[t]{10}{*}{ Trimethoprim-sulfamethoxazole } & 23 & 100 & na & $0.06 / 1.19$ & $0.03 / 0.59-0.5 / 9.5$ & Johnson et al $2006^{49}$ \\
\hline & 152 & 100 & $\leq 0.25$ & $\leq 0.25$ & $\leq 0.25$ & Sader et al $2008^{76}$ \\
\hline & 157 & 100 & na & na & na & King et al $2006^{89}$ \\
\hline & 127 & 100 & na & na & na & Huang et al $2006^{88}$ \\
\hline & 186 & 98.3 & na & na & na & Crum et al $2006^{86}$ \\
\hline & 60 & 98 & $0.06 / 1.19$ & $0.5 / 9.5$ & $0.03 / 32-0.59 / 608$ & Saravolatz et al $2007^{44}$ \\
\hline & 342 & 97 & na & na & na & Naimi et al $200 I^{90}$ \\
\hline & 1218 & 97 & na & na & na & Fridkin et al $2005^{87}$ \\
\hline & 200 & 92 & 0.25 & 1 & $0.03->8$ & Tsuji et al $2007^{91}$ \\
\hline & 1989 & 91.1 & $\leq 0.5$ & $\leq 0.5$ & $\leq 0.5->2$ & Mendes et al $2008^{45}$ \\
\hline \multirow[t]{9}{*}{ Vancomycin ${ }^{\mathrm{a}}$} & 23 & 100 & na & 0.5 & $0.25-0.5$ & Johnson et al $2006^{49}$ \\
\hline & 1989 & 100 & I & 1 & $0.25-4$ & Mendes et al $2008^{45}$ \\
\hline & 60 & 100 & 0.5 & 0.5 & $0.25-1$ & Saravolatz et al $2007^{44}$ \\
\hline & 152 & 100 & I & I & $0.5-2$ & Sader et al $2008^{76}$ \\
\hline & 157 & 100 & na & na & na & King et al $2006^{89}$ \\
\hline & 1345 & 100 & na & na & na & Fridkin et al $2005^{87}$ \\
\hline & 127 & 100 & na & na & na & Huang et al $2006^{88}$ \\
\hline & 343 & 100 & na & na & na & Naimi et al $2001^{90}$ \\
\hline & 200 & 100 & 2 & 2 & $0.5-2$ & Tsuji et al $2007^{91}$ \\
\hline
\end{tabular}

${ }^{a}$ Not all vancomycin data are reflective of Clinical and Laboratory Standards Institute breakpoint changes made in 2006 specific to Staphylococcus aureus and may overestimate susceptibility.

Abbreviation: na, not available.

resistance in erythromycin-resistant, clindamycin-susceptible S. aureus isolates. ${ }^{27}$ While the rate of resistance to clindamycin continues to be low in CA-MRSA, the frequency of inducible resistance is variable and unknown. ${ }^{28}$ Therefore, if confirmatory D-testing is not available, clindamycin should not be used to treat erythromycin-resistant CA-MRSA.

\section{Tetracyclines}

Doxycycline (Vibramycin $^{\circledR}$; Pfizer, Inc, New York, NY, USA) and minocycline (Minocin ${ }^{\circledR}$; Wyeth Pharmaceuticals,
Philadelphia, PA, USA) can also be effective in treating CA-MRSA SSSI. ${ }^{29,30}$ Although there are limited published data, the long-acting tetracyclines appear to be good treatment options in most tetracycline-susceptible MRSA SSSI. ${ }^{31}$ Most laboratories in the United States test S. aureus for susceptibility to tetracycline (Sumycin ${ }^{\circledR}$; Par Pharmaceuticals, Spring Valley, NY, USA) and not doxycycline or minocycline. ${ }^{32}$ The use of tetracycline as a surrogate may overestimate the prevalence of resistance to doxycycline or minocycline since there are two different 
genes that confer resistance, tet $M$ and tetK. Tet $K$ confers resistance to tetracycline, while tet $M$ confers resistance to all agents in the class. Tet $K$ has been the predominant gene associated with resistant isolates of MRSA in the community, which points towards the continued use and effectiveness of doxycycline and minocycline. ${ }^{33}$

\section{Linezolid}

Linezolid (Zyvox ${ }^{\circledR}$; Pfizer, Inc, New York, NY, USA) may be a reasonable alternative following failure of treatment or allergic reactions. ${ }^{34}$ It is a bacteriostatic antimicrobial approved to treat MRSA complicated-SSSI (cSSSI). Controlled trials with linezolid versus vancomycin determined them to be comparable in treatment of MRSA cSSSI. ${ }^{35}$ Though resistance to linezolid is rare, the possibility of resistance has emerged with its increased use. ${ }^{36}$ Similar to clindamycin, linezolid also suppresses the PVL toxin in CA-MRSA. This may prove beneficial in severe human infections with necrosis. ${ }^{37}$

\section{Other antimicrobials}

Rifampin (Rifadin ${ }^{\circledR}$; Sanofi-Aventis, Bridgewater, NJ, USA) should never be used as a single agent for the treatment of MRSA SSSI because of the rapid resistance that can develop in $S$. aureus. ${ }^{38,39}$ Rifampin can be used in combination with other antimicrobial agents for potential eradication enhancement, but there is lack of evidence through studies, available for the benefit. ${ }^{40}$

Due to the relative ease of $S$. aureus in developing resistance with fluoroquinolone usage, they cannot be recommended for use in MRSA SSSI. The fluoroquinolones can cause chromosomal mutations in genes encoding the subunits of the drugs' target enzymes, DNA gyrase and topoisomerase IV. ${ }^{41}$

\section{Parenteral treatment options}

Several parenteral agents are currently available for the treatment of serious infections caused by MRSA, regardless of the strain, which include vancomycin (or teicoplanin), Q/D, linezolid, daptomycin, and tigecycline (Table 4). While vancomycin has long been used for the treatment of MRSA, increasing resistance has begun to limit its use in contemporary clinical practice. ${ }^{85}$ Vancomycin has long been considered the "gold standard" for the treatment of MRSA, but recent reports of treatment failures are causing concern. ${ }^{42}$ Since the emergence of CA-MRSA, limited attention has been directed toward the efficacy of vancomycin due to the availability of multiple new compounds. Of the remaining parenteral agents, linezolid is the only agent with an oral formulation and has been previously discussed.

\section{Quinupristin/dalfopristin (Q/D)}

Q/D (Synercid ${ }^{\circledR}$; Monarch Pharmaceuticals, Bristol, TN, USA) is a semisynthetic streptogramin antibiotic with a potent gram-positive spectrum of activity, including CA-MRSA. ${ }^{43-45}$ Prospective randomized controlled trials support its use for the treatment of bacteremia caused by vancomycin-resistant Enterococcus faecium and for cSSSI caused by MSSA or Streptococcus pyogenes. ${ }^{43,46,47}$ Despite previously demonstrated in vitro activity, Q/D lacks an indication in MRSA infections because this pathogen was not isolated in sufficient quantity to be evaluated. Historically the use of Q/D has been limited due to the high incidence of adverse reactions. Use is generally reserved for patients in whom conventional therapy is not tolerated or is otherwise contraindicated.

\section{Daptomycin}

Daptomycin (Cubicin ${ }^{\circledR}$; Cubist Pharmaceuticals, Lexington, MA, USA) is a lipoglycopeptide antibiotic with a potent in vitro gram-positive spectrum of activity, specifically with rapid bactericidal action against MRSA. ${ }^{48}$ Additional in vitro data have also demonstrated the activity of daptomycin against CA-MRSA. ${ }^{44,49}$ However, some data suggest a relationship between decreased susceptibility of vancomycin to MRSA and a decreased susceptibility of daptomycin to MRSA. ${ }^{50-53}$ Randomized controlled trials support the use of daptomycin for the treatment of cSSSI due to susceptible strains of gram-positive pathogens, and for the treatment of bacteremia and right-sided endocarditis caused by $S$. aureus. ${ }^{54,55}$ MRSA was the pathogen identified at baseline in $9.3 \%(n=40)$ of daptomycin-treated patients in the cSSSI trials and $37.4 \%(n=45)$ in the right-sided endocarditis trial. ${ }^{54,55}$ The MRSA strains in these trials were not differentiated into HA-MRSA or CA-MRSA. Outcomes were found to be similar between daptomycin and comparator for infections caused by MRSA. Prospective outcome data, however, are lacking for the treatment of CA-MRSA infections specifically. A retrospective evaluation assessed the use of daptomycin for the treatment of communityphenotype-MRSA (CP-MRSA) infections, defined by the authors as MRSA with susceptibility to both clindamycin and TMP-SMX. ${ }^{56}$ All other phenotypes were classified by the authors as other-phenotype-MRSA (OP-MRSA). Of the 352 patients included in this evaluation, 100 were classified 
Table 3 Antimicrobials recommended for outpatient treatment of suspected methicillin-resistant (MRSA) skin and skin structure infections Selection of empiric therapy should be guided by local susceptibility and modified based on results of culture and susceptibility testing. The duration of therapy for most SSSI is 7-10 days, but may vary depending upon the severity of infection and clinical response. Some infections may require a more prolonged treatment course.

\begin{tabular}{|c|c|c|c|}
\hline Antimicrobial & Adult dose & Pediatric dose & Considerations \\
\hline Clindamycin' & $300-450$ mg PO QID & $\begin{array}{l}10-20 \mathrm{mg} / \mathrm{kg} \text { PO per DAY } \\
\text { divided into } 3-4 \text { doses per day; } \\
\text { not to exceed adult dose. }\end{array}$ & See below ${ }^{1}$ \\
\hline Doxycycline or minocycline ${ }^{2}$ & 100 mg PO BID & $\begin{array}{l}\text { Do not use in children }<8 \text { years } \\
\text { old. Age } \geq 8 \text { years old: } 4 \mathrm{mg} / \mathrm{kg} \\
\text { PO per DAY divided BID; } \\
\text { not to exceed adult dose. }\end{array}$ & $\begin{array}{l}\text { Chelated by divalent cations. Separate } \\
\text { from iron, calcium, and multivitamins. } \\
\text { May make skin more sensitive to } \\
\text { sunlight, sunburn may result. Do not } \\
\text { use if pregnant or breastfeeding. }\end{array}$ \\
\hline Linezolid $^{3}$ & 600 mg PO BID & $\begin{array}{l}\text { Age }>7 \text { days-II years old: } \\
\text { I0 mg/kg PO per DOSE given } \\
\text { every } 8 \text { hours; not to exceed } \\
\text { I } 200 \mathrm{mg} \text { daily. } \\
\text { Age } \geq 12 \text { years old: } 600 \mathrm{mg} \\
\text { PO BID. }\end{array}$ & $\begin{array}{l}\text { Low-tyramine diet required. Avoid } \\
\text { concominant MAO-I or SSRI agents } \\
\text { due to potential for serotonin } \\
\text { syndrome. Monitor CBC with } \\
\text { prolonged courses (potential for } \\
\text { leukopenia, thrombocytopenia). } \\
\text { Monitor for peripheral neuropathy. }\end{array}$ \\
\hline Rifampin $^{4}$ & 300 mg PO BID & $\begin{array}{l}15-20 \mathrm{mg} / \mathrm{kg} \text { PO per DAY } \\
\text { divided BID; not to exceed } \\
600 \mathrm{mg} \text { daily. }\end{array}$ & $\begin{array}{l}\text { NUMEROUS CYP450 drug-drug } \\
\text { interactions. INR should be closely } \\
\text { followed (for rapid decrease) in } \\
\text { patients on warfarin. Causes bodily } \\
\text { fluids (urine, sweat, etc.) to turn } \\
\text { orange/red while on therapy. }\end{array}$ \\
\hline Trimethoprim-sulfamethoxazole ${ }^{2}$ & $\begin{array}{l}\text { I-2 DS tablets (160 mg TMP/ } \\
800 \mathrm{mg} \text { SMX per tab) PO BID. } \\
\text { May consider dose increase for } \\
\text { morbidly obese patients } \\
\text { (8-10 mg/kg TMP per DAY } \\
\text { divided BID-TID, maximum dose } \\
2 \text { DS tablets TID). }\end{array}$ & $\begin{array}{l}\text { Base dose on TMP. Age } \\
\geq 2 \text { months: } 8-2 \mathrm{mg} / \mathrm{kg} \text { TMP } \\
(40-60 \mathrm{mg} / \mathrm{kg} \text { SMX) PO per DAY } \\
\text { divided BID; not to exceed } \\
\text { adult dose. }\end{array}$ & $\begin{array}{l}\text { Dose adjustment required in } \\
\text { renal dysfunction. Significant drug } \\
\text { interaction with warfarin; INR } \\
\text { should be closely followed for rapid } \\
\text { increase. Avoid in patients with G6PD } \\
\text { deficiency. May make skin more sensi- } \\
\text { tive to sunlight, sunburn may result. }\end{array}$ \\
\hline
\end{tabular}

'Clindamycin resistance is becoming increasingly prevalent. Pay close attention to the patient's culture and sensitivity reports when considering Clindamycin use. Clindamycin should not be used if isolate is erythromycin resistant or if "inducible resistance" is present (D-test).

${ }^{2}$ For cellulitis of unknown cause where Group A Streptococcus may be a concern, clindamycin in combination with doxycycline/minocycline provides additional coverage for both organisms. Adjunctive clindamycin therapy may also be useful in toxigenic Staphylococci/Streptococci infections.

${ }^{3}$ Due to significant drug interactions and expense, infectious disease consultation is recommended when considering linezolid.

${ }^{4}$ Rifampin must always be used in combination with another antibiotic.

Notes: Outpatient use of fluoroquinolones or macrolides is NOT RECOMMENDED for routine treatment of MRSA. Resistance to fluoroquinolones can develop rapidly on therapy, so these agents should not be routinely used even if the isolate is reported to be susceptible. Consider a consultation with an infectious disease physician before prescribing. Abbreviations: SSSI, skin and skin structure infections; MAO-I, monoamine oxidase inhibitor; SSRI, selective serotonin reuptake inhibitor; CBC, complete blood count; INR, international normalized ratio; G6PD, glucose-6-phosphate dehydrogenase.

as CP-MRSA and 252 as OP-MRSA. The CP-MRSA group tended to be younger with fewer underlying diseases. Success rate, time to clinical response, and duration of therapy were similar in both groups, prompting the authors to conclude that daptomycin was equally efficacious for the treatment of CP-MRSA or OP-MRSA infections in this select group of patients. However, these data cannot necessarily be extrapolated to all patient populations.

\section{Tigecycline}

Tigecycline (Tygacil ${ }^{\circledR}$; Wyeth Pharmaceuticals, Philadelphia, PA, USA), the first glycycline antibiotic, has a broad range of in vitro activity against most gram-positive (including MRSA), most gram-negative, and anaerobic bacteria. ${ }^{57}$ Mendes and colleagues evaluated tigecycline against 1989 human isolates of CA-MRSA collected from the SENTRY Antimicrobial Surveillance Program, 94.7\% of which were PVL positive. ${ }^{45}$ Tigecycline was active against $98.2 \%$ of the strains tested, similar to the susceptibility rates for vancomycin, teicoplanin, Q/D and linezolid. Randomized controlled clinical trials have demonstrated its safety and efficacy for the treatment of cSSSI and complicated intra-abdominal infections (cIAI). ${ }^{58,59}$ While MRSA has been included in the FDA approval for its association to cSSSI, it is lacking 
Table 4 Parenteral agents for the treatment of severe community-associated methicillin-resistant Staphylococcus aureus infections ${ }^{34,43,48,57,85}$

\begin{tabular}{|c|c|c|c|c|}
\hline Drug & Drug class & Indication & Dose (Intravenous) & Considerations \\
\hline Daptomycin & Lipoglycopeptide & $\begin{array}{l}\text { cSSSI, bacteremia with right-sided } \\
\text { infective endocarditis }\end{array}$ & $\begin{array}{l}4-6 \mathrm{mg} / \mathrm{kg} \text { (actual body } \\
\text { weight) every } 24 \text { hours }\end{array}$ & $\begin{array}{l}\text { Dose adjust to every } \\
48 \text { hours if } \mathrm{CrCl} \\
<30 \mathrm{~mL} \text { min. Monitor CPK }\end{array}$ \\
\hline Linezolid & Oxazolidinone & $\begin{array}{l}\text { uSSSI, cSSSI, CAP including } \\
\text { concurrent bacteremia, NP }\end{array}$ & $600 \mathrm{mg}$ every 12 hours & $\begin{array}{l}\text { Low-tyramine diet } \\
\text { required. Avoid } \\
\text { concominant MAO-I } \\
\text { or SSRI agents due to } \\
\text { potential for serotonin } \\
\text { syndrome. Monitor CBC } \\
\text { with prolonged courses } \\
\text { (potential for leukopenia, } \\
\text { thrombocytopenia). } \\
\text { Monitor for peripheral } \\
\text { neuropathy. }\end{array}$ \\
\hline Quinupristin-dalfopristin & Streptogramin & Bacteremia, cSSSI & $\begin{array}{l}7.5 \mathrm{mg} / \mathrm{kg} \text { (actual body } \\
\text { weight) every } 8-12 \text { hours }\end{array}$ & $\begin{array}{l}\text { Monitor LFTs. Use often } \\
\text { limited by high inci- } \\
\text { dence of arthralgias and } \\
\text { myalgias. }\end{array}$ \\
\hline Tigecycline & Glycylcycline & cSSSI, cIAI & $\begin{array}{l}100 \mathrm{mg} \text { once, then } \\
50 \mathrm{mg} \text { every } 12 \text { hours }\end{array}$ & $\begin{array}{l}\text { Does not achive optimal } \\
\text { concentrations in } \\
\text { blood or urine as highly } \\
\text { distributed to the tissues. }\end{array}$ \\
\hline Vancomycin & Glycopeptide & $\begin{array}{l}\text { Severe gram-positive } \\
\text { infections }\end{array}$ & $15 \mathrm{mg} / \mathrm{kg}$ every 12 hours & $\begin{array}{l}\text { Dose adjust in renal } \\
\text { dysfunction. Monitor } \\
\text { levels and SCr. }\end{array}$ \\
\hline
\end{tabular}

Abbreviations: cSSSI, complicated skin and skin structure infections; uSSSI, uncomplicated skin and skin structure infections; CAP, community-acquired pneumonia; NP, nosocomial pneumonia; clAl, complicated intra-abdominal infections; SCr, serum creatinine; LFTs, liver function tests; MAO-I, monoamine oxidase inhibitor; SSRI, selective serotonin reuptake inhibitor; $\mathrm{CBC}$, complete blood count; $\mathrm{CrCl}$, creatinine clearance; $\mathrm{CPK}$, creatine phosphokinase.

for cIAI due to a small sample size in the registration trials, similar to Q/D. A retrospective evaluation of the 173 MRSA isolates obtained from these phase III trials, $85 \%$ of which were from the cSSSI trial, found that 76 isolates had characteristics consistent with known CA-MRSA on the basis of genotyping and the presence of both PVL-encoding locus and SCCmec type IV. ${ }^{60}$ All strains demonstrated in vitro susceptibility to tigecycline.

\section{Drugs under investigation}

Multiple antimicrobial agents with potent in vitro MRSA activity are currently in development. These agents are summarized in Table 5 with regard to drug name, route of administration, dose, indication for which it is under evaluation, and phase of development at this point of time. Drug classes currently in clinical use with additional drugs in development include glycopeptides, oxazolidinones, and a dihydrofolate reductase inhibitor. In addition, for the first time ever, beta-lactam antibiotics which possess MRSA activity, specifically new cephalosporins and carbapenems, are being developed.

\section{Glycopeptides}

Adding to vancomycin and teicoplanin of the glycopeptide drug class, dalbavancin, telavancin, and oritavancin are currently in the developmental stage. Dalbavancin is a semisynthetic lipoglycopeptide with a long half-life allowing for once-weekly dosing. ${ }^{61}$ Building on a successful phase II trial evaluating dalbavancin versus standard-of-care, a phase III trial evaluated dalbavancin versus linezolid for the treatment of cSSSI. ${ }^{62,63}$ MRSA was identified in 51\% of patients from whom a pathogen was isolated at baseline. Dalbavancin was well tolerated and efficacy was found to be noninferior. A phase II trial for bacteremia has yielded similar results. ${ }^{64}$ In an in vitro evaluation of 329 pathogens associated with diabetic foot infections (DFIs), susceptibility to dalbavancin was compared with other antimicrobial agents. ${ }^{65}$ Of these 329 pathogens, 60 were MRSA, with an estimated 50\% suspected CA-MRSA. Though this was not confirmed via pulse field gel electrophoresis (PFGE), $>50 \%$ of the suspected CA-MRSA isolates were resistant to clindamycin with an $\mathrm{MIC}>8 \mu \mathrm{g} / \mathrm{mL}$. The authors observed that dalbavancin was more active than vancomycin, daptomycin, and linezolid 
against MRSA. They concluded that the in vitro data, coupled with dalbavancin outcome data (versus linezolid for the treatment of SSSI, including DFI), indicate that it may provide an advantage to patients with DFI in emergency departments, inpatient settings, and outpatient settings.

Telavancin, another lipoglycopeptide, possesses potent MRSA activity. ${ }^{66}$ An in vitro evaluation tested telavancin against 60 strains of CA-MRSA (as defined by the CDC). ${ }^{44}$ Thirty-two (54\%) of the 60 CA-MRSA strains were identified via PFGE to be the USA300 strain which harbors PVL genes. Telavancin demonstrated bactericidal activity against all 60 CA-MRSA isolates, including all USA300 strains. A phase III study found telavancin to be safe and at least as effective as vancomycin for the treatment of cSSSI caused by grampositive organisms, including MRSA.${ }^{67}$ Many of the MRSA isolates were SCCmec type IV and PVL positive. ${ }^{68}$

Oritavancin, another semisynthetic lipoglycopeptide with MRSA activity, has a long half-life allowing for less frequent dosing compared to contemporary glycopeptides. ${ }^{69}$ Two phase III trials have been completed evaluating oritavancin versus comparator for the treatment of $\mathrm{cSSSI}^{70,71}$
Although these data are as yet unpublished, favorable results have been reported in abstract form and a new drug application (NDA) was submitted to the FDA in early 2008 for the treatment of cSSSI. Additional data specific to CA-MRSA are lacking.

\section{Oxazolidinones}

Several oxazolidinones are currently in development. While multiple compounds are under investigation, most are in pre-clinical development stage and have not yet been named beyond their chemical number. AZD2563, for example, has demonstrated in vitro activity similar to linezolid against gram-positive pathogens, including MRSA. ${ }^{72}$ Additional oxazolidinones have been evaluated by McKee and colleagues, but they are far from clinical development. ${ }^{73}$

\section{Dihydrofolate reductase inhibitor}

Iclaprim, a dihydrofolate reductase inhibitor similar to trimethoprim, is currently being evaluated as an intravenous formulation for the treatment of cSSSI in phase III trials.

Table 5 Investigational agents with in vitro activity against methicillin-resistant Staphylococcus aureus

\begin{tabular}{|c|c|c|c|c|}
\hline Drug & Route & Dose & $\begin{array}{l}\text { Indication under } \\
\text { evaluation }\end{array}$ & Phase \\
\hline \multicolumn{5}{|l|}{ Carbapenem } \\
\hline Multiple in early development & na & na & na & pre-clinical \\
\hline \multicolumn{5}{|l|}{ Cephalosporin } \\
\hline Ceftopbiprole & iv & $500 \mathrm{mg}$ every 12 hours & cSSSI & III \\
\hline Ceftaroline & iv & $500 \mathrm{mg}$ every 12 hours & cSSSI & III \\
\hline \multicolumn{5}{|c|}{ Dihydrofolate reductase inhibitor } \\
\hline \multirow[t]{4}{*}{ Iclaprim } & iv & $0.8 \mathrm{mg} / \mathrm{kg}$ every & cSSSI & III \\
\hline & & 24 hours & & \\
\hline & iv & na & HAP (VAP and HCAP) & II \\
\hline & $\begin{array}{l}\text { iv to enteral } \\
\text { switch }\end{array}$ & na & cSSSI & II \\
\hline \multicolumn{5}{|l|}{ Oxazolidinone } \\
\hline Multiple in early development & na & na & na & pre-clinical \\
\hline \multicolumn{5}{|l|}{ Synthetic glycopeptide } \\
\hline \multirow[t]{2}{*}{ Dalbavancin } & iv & $\begin{array}{l}1000 \mathrm{mg} \text { on day I, } \\
500 \mathrm{mg} \text { on day } 8\end{array}$ & cSSSI & III \\
\hline & iv & $\begin{array}{l}1000 \mathrm{mg} \text { on day I, } \\
500 \mathrm{mg} \text { on day } 8\end{array}$ & bloodstream & II \\
\hline Ortivancin & iv & $\begin{array}{l}200 \text { mg every } \\
24 \text { hours }\end{array}$ & cSSSI & III \\
\hline Telavancin & iv & $\begin{array}{l}10 \mathrm{mg} / \mathrm{kg} \text { every } \\
24 \text { hours }\end{array}$ & cSSSI & III \\
\hline
\end{tabular}

Abbreviations: iv, intravenous; cSSSI, complicated skin and skinstructure infections; HAP, hospital-acquired pneumonia; VAP, ventilator-acquired pneumonia; HCAP, healthcareassociated pneumonia; na, not applicable. 
Positive outcomes have resulted in the submission of a NDA to the FDA., though the FDA has denied its approval. Iclaprim is currently under review in Europe and Canada. An intravenous-to-oral switch of iclaprim for the treatment of cSSSI is under evaluation in a phase II trial. Additionally, intravenous iclaprim for the treatment of hospital-acquired pneumonia, including both ventilator-associated pneumonia and healthcare-associated pneumonia is under evaluation in a phase III trial. Data specific to CA-MRSA are lacking.

\section{Cephalosporins}

Traditionally, cephalosporins have lacked activity against MRSA. Recently this changed with the introduction of ceftobiprole and ceftaroline which have a high affinity for PBP2a, and therefore exhibit good in vitro activity against MRSA, including CA-MRSA. ${ }^{74-76}$ When tested against 152 strains of well-characterized CA-MRSA, the $\mathrm{MIC}_{50}$ and $\mathrm{MIC}_{90}$ for ceftobiprole were 0.5 and $0.5 \mu \mathrm{g} / \mathrm{mL}$, respectively, with a range of $0.25-1 \mu \mathrm{g} / \mathrm{mL}$. Breakpoints have not yet been established and consequently these results are up for interpretation. Both ceftaroline and ceftobiprole are currently under investigation for safety and efficacy of the treatment of cSSSI; a NDA has since been filed with the FDA for ceftobiprole.

\section{Carbapenems}

Similar to the aforementioned cephalosporins, some investigational carbapenems have demonstrated in vitro activity against MRSA. Specifically, ME1036 has demonstrated activity against CA-MRSA. ${ }^{76}$ When tested against 152 strains of well-characterized CA-MRSA, the $\mathrm{MIC}_{50}$ and $\mathrm{MIC}_{90}$ were 0.12 and $0.25 \mu \mathrm{g} / \mathrm{mL}$, respectively, with a range of $0.06-0.5 \mu \mathrm{g} / \mathrm{mL}$. This, and other carbepenems with MRSA activity, are in the early stages of clinical development and may not reach market for several years. A review by Lo and colleagues has examined these agents in more detail. ${ }^{77}$

\section{Complementary/alternative medicine}

Tea tree oil (TTO) has been evaluated as a potential agent for both MRSA decolonization and treatment. It is available in many forms and is widely used in cosmetic preparations. Concentrations of TTO and product integrity are often variable since it is not a regulated drug.

Several studies have evaluated the in vitro activity of TTO versus MRSA and many have shown promise, including one study indicating that TTO may be of benefit for eradication of MRSA biofilms. ${ }^{78}$ Translating in vitro data to clinical practice has yielded less consistent results. A study by Dryden and colleagues evaluated TTO for MRSA eradication in hospitalized patients. ${ }^{79}$ A standard 5-day regimen of mupirocin $2 \%$ nasal ointment, chlorhexidine gluconate $4 \%$ skin cleanser and silver sulfadiazine $1 \%$ cream was compared to $10 \%$ tea tree cream and 5\% tea tree body wash. Results indicated that mupirocin was significantly more effective at eradicating MRSA nasal carriage compared to TTO, $78 \%$ and $41 \%$ clearance, respectively.

A study by McMahon and colleagues investigated whether the effect of sub-lethal challenge with TTO impacted the antibiotic resistance profiles of significant human pathogens. ${ }^{80}$ The authors note that TTO products often contain variable concentrations, and previously available data had not evaluated the impact of inappropriate or sublethal TTO concentrations. With respect to the MRSA strains used in the study, TTO caused an increased (2-fold or greater) MIC value for 7 out of 10 antibiotics tested.

In summary, before TTO is widely accepted as a standardof-care for treating MRSA or for MRSA decolonization, further clinical trial data are needed. If providers recommend TTO for treatment of CA-MRSA, it should be in conjunction with one of the traditional therapies previously discussed in this article.

\section{Resistance}

As discussed, most of the USA300 isolates are resistant to beta-lactam and macrolide antibiotics. Given that there are often other oral agents to treat most CA-MRSA strains, the question of development of resistance to these (doxycyline, minocycline, clindamycin, TMP-SMX) drugs is of concern. An epidemiologic study evaluated 123 USA300 isolates collected in an ambulatory health center in Boston, Massachusetts. ${ }^{81}$ Of all the isolates, $83 \%$ had PFGE revealing either USA300-0114 (58\% of total isolates) or USA300-0247 (24\% of total isolates). There were 12 multidrug-resistant (MDR) isolates reported, all of which contained the tet $\mathrm{K}$ and $e r m \mathrm{C}$ genes. Of the USA300-0114 isolates $(n=73)$, $72(99 \%)$ were resistant to erythromycin, 36 (49\%) were resistant to clindamycin and $10(14 \%)$ were resistant to doxycycline. Two of the strains showed multidrug resistance to erythromycin, levofloxacin, clindamycin and tetracycline. Of the USA 300-0247 isolates $(n=29), 26(90 \%)$ were resistant to erythromycin, $22(76 \%)$ were resistant to clindamycin and $21(72 \%)$ were resistant to tetracycline. Sixteen of the strains showed multidrug resistance to erythromycin, levofloxacin, clindamycin and tetracycline. Twelve isolates were tested for mupirocin susceptibility, and all were mupirocin resistant with $\mathrm{MIC} \geq 128 \mu \mathrm{g} / \mathrm{mL}$. The authors note that their resistance rates were considerably 
higher than other reported data as well as compared to the local health network.

A second retrospective study describes a USA300 strain that exhibits plasmid-mediated resistance to erythromycin, clindamycin and mupirocin. ${ }^{82}$ This retrospective study aimed to determine the incidence of an MDR MRSA clone (USA300) in San Francisco and risk factors associated with it. Based on an analysis from nine medical centers, the annual incidence of USA300 infection in San Francisco was estimated to be 275 cases per 100000 persons (95\% CI, 256-295 cases per 100000 persons). With respect to USA300 infections containing a MDR conjugative plasmid, the annual incidence was 26 per 100000 persons (95\% CI, 16-36 cases per 100000 persons). When eight zip codes were pooled, the incidence rose to 59 cases per 100000 persons (95\% CI, 36-82 cases per 100000 persons). The other 18 zip codes evaluated only had incidence or 4 per 100000 persons (95\% CI, 0-8 cases per 100000 persons). A single zip code had $25.7 \%$ of male same-sex couples, and incidence of MDR USA300 was 170 cases per 100000 persons (95\% CI, 41-299 cases per 100000 persons). The authors conclude that men who have sex with men may be at higher risk for infection with MDR USA300.
Data such as these reflect the need for astute monitoring of local epidemiologic patterns for CA-MRSA isolates.

\section{Outpatient treatment approach}

The treatment approach for CA-MRSA infections is variable based upon severity and site of infection. As discussed previously in this article, the majority of CA-MRSA infections are cutaneous infections and many may be managed on an outpatient basis. While the general consensus is that minor infections can be managed by incision and drainage (I\&D) alone, many practitioners are opting to also treat with oral antimicrobials when MRSA diagnosis is confirmed by culture. A study by Moran and colleagues evaluated CAMRSA patients presenting to the Emergency Department. ${ }^{83}$ Approximately $20 \%$ of patients underwent I\&D alone, $10 \%$ were treated with antibiotics alone, and $66 \%$ received both I\&D and antibiotic therapy. The 2005 Infectious Diseases Society of America Practice Guideline for the Diagnosis and Management of Skin and Soft-Tissue Infections recommends that if the infection involves inflammation of the surrounding tissue or has manifested in systemic symptoms, I\&D with concomitant antimicrobial therapy. ${ }^{84}$ Figure 1 summarizes a

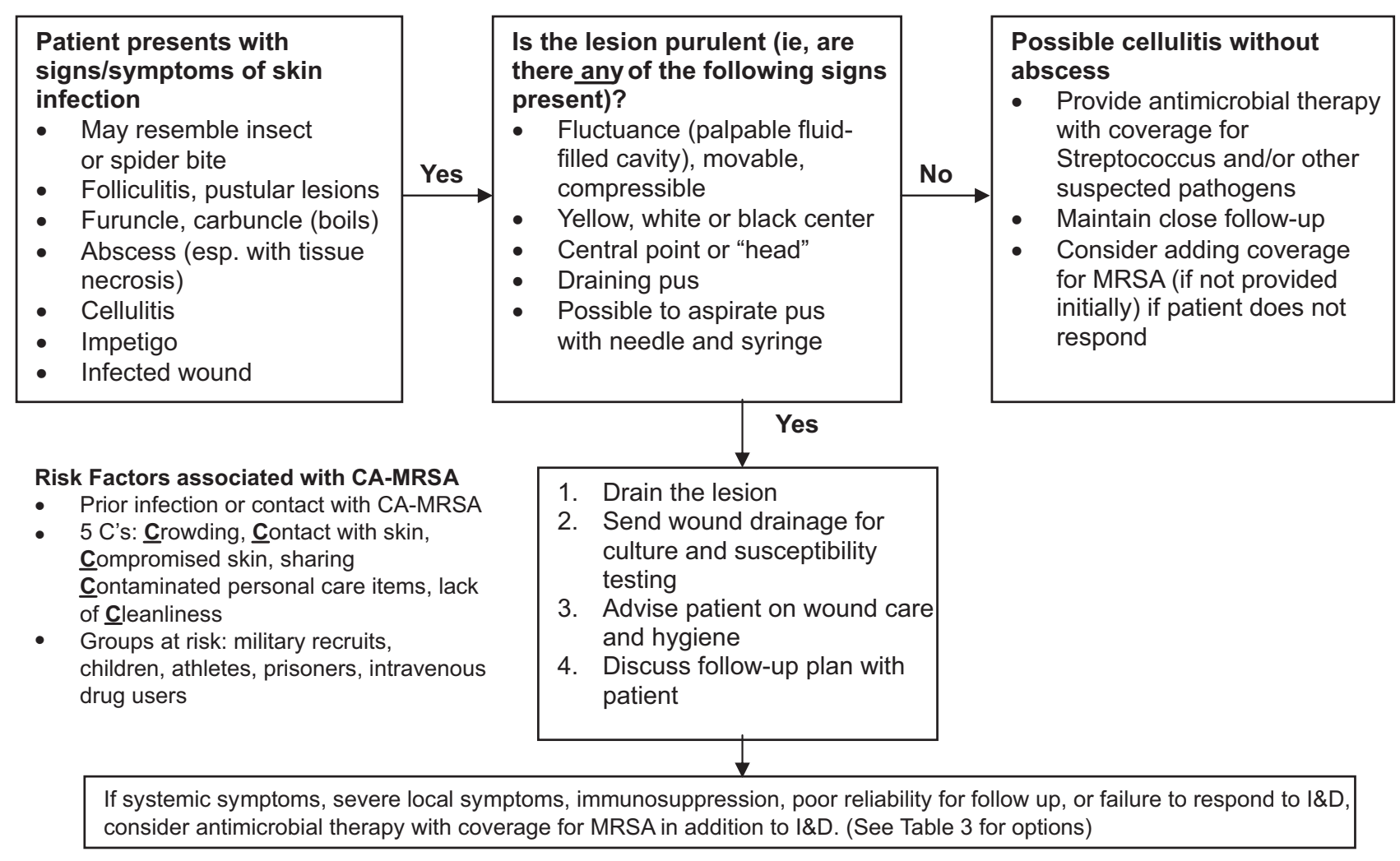

Figure I Outpatient management of suspected community-associated methicillin-resistant Staphylococcus aureus skin and skin structure infections. Adapted from Aurora Health Care MRSA Clinical Guidelines 2008. Kathryn Leonhardt, MD, MPH, Editor.

Abbreviations: I\&D, incision and drainage; MRSA, methicillin-resistant S. aureus; CA-MRSA, community-associated MRSA. 
possible treatment approach for the outpatient management of suspected CA-MRSA SSSI.

\section{Conclusions}

Although the changing epidemiology of MRSA has become better understood in recent years, the impact, both in and out of the hospital, still require further research and investigation. Understanding how to treat and prevent CA-MRSA is critical. Risk factors, optimal treatment, and infection prevention strategies need to be better defined and economic outcomes need to be measured. The most effective intervention appears to be prevention although this is one of the most difficult. As clinicians and patients become more educated about CAMRSA and its spread, common practices will likely require modification.

\section{Disclosures}

The authors report no conflicts of interest in this work.

\section{References}

1. Jevons MP, Coe AW, Parker MT. Methicillin resistance in staphylococci. Lancet. 1963;1:904-907.

2. Boucher HW, Corey GR. Epidemiology of methicillin-resistant Staphylococcus aureus. Clin Infect Dis. 2008;46:S344-S349.

3. Wallin TR, Hern HG, Frazee BW. Community-associated methicillinresistant Staphylococcus aureus. Emerg Med Clin N Am. 2008;26: $431-455$.

4. Johnson LB, Saravolatz LD. Community-acquired MRSA: current epidemiology and management issues. Infect Med. 2005;22(1):16-20.

5. File TM. Impact of Community-associated methicillin-resistant Staphylococcus aureus in the hospital setting. Cleve Clin J Med. 2007; 74:S6-S11.

6. Naimi TS, LeDell KH, Como-Sabetti K, et al. Comparison of Community- and health care-associated methicillin-resistant Staphylococcus aureus infection. JAMA. 2003;290:2976-2984.

7. Center for Disease Control MRSA definition reference http://www.cdc. gov/ncidod/dhqp/ar_mrsa_ca_clinicians.html\#4. Accessed October 20, 2008.

8. Otter JA, French GL. Nosocomial transmission of community-acquired methicillin-resistant Staphylococcus aureus: an emerging threat. Lancet Infect Dis. 2006;6:753.

9. Maree CL, Daum RS, Boyle-Vavra S, et al. Community-associated methicillin-resistant Staphylococcus aureus causing healthcareassociated infections. Emerg Infect Dis. 2007;13:236-242.

10. Daum RS. Skin and soft tissue infections caused by methicillin-resistant Staphylococcus aureus. N Engl J Med. 2007;357:380-390.

11. Gillet Y, Vanhems P, Lina G, et al. Factors predicting mortality in necrotizing community-acquired pneumonia caused by Staphylococcus aureus containing Panton-Valentine leukocidin. Clin Infect Dis. 2007; 45:315-321.

12. Gillet Y, Issartel B, Vanhems P, et al. Association between Staphylococcus aureus strains carrying gene for Panton-Valentine leukocidin and highly lethal necrotising pneumonia in young immunocompetent patients. Lancet. 2002;359:753-759.

13. Weber, JT. Community-associated methicillin-resistant Staphylococcus aureus. Clin Infect Dis. 2005;41(10):1373-1406.

14. Miller LG, Diep BA. Colonization, fomites, and virulence: rethinking the pathogenesis of community-associated methicillin-resistant Staphylococcus aureus infections. Clin Infect Dis. 2008;46:752-760.
15. Kazakova SV, Hageman JC, Matava M, et al. A clone of methicillinresistant Staphylococcus aureus among professional football players. N Engl J Med. 2005;352:468-475.

16. Salgado CD, Farr BM, Calfee DP. Community-acquired methicillinresistant Staphylococcus aureus: a meta-analysis of prevalence and risk factors. Clin Infect Dis. 2003;36(2):131-139.

17. Weber JT. Community-associated methicillin-resistant Staphylococcus aureus. Clin Infect Dis. 2005;41:S269-S272.

18. Stevens DL, Bisno AL, Chambers HF, et el. Practice guidelines for the diagnosis and management of skin and soft-tissue infections. Clin Infect Dis. 2005;41(10):1373-1406.

19. Ruhe JJ, Smith N, Bradsher RW, et al. Community onset of methicillin-resistant Staphylococcus aureus skin anad soft tissue infections: Impact of antimicrobial therapy outcome. Clin Infect Dis. 2007;44: 777-784.

20. Gorwitz RJ, Jernigan DB, Powers JH, et al. Strategies for clinical management of MRSA in the community: Summary of an experts' meeting convened by the Centers for Disease Control and Prevention. 2006. Available at http://www.cdc.gov/ncidod/dhqp/ ar_mrsa_ca.html. 2006.

21. Septra ${ }^{\circledR}$ [package insert]. Bristol, TN, USA: King Pharmaceuticals; 2007.

22. Kaka AS, Rueda AM, Shelburne SA III, et al. Bactericidal activity of orally available agents against methicillin-resistant Staphylococcus aureus. J Antimicrob Chemother. 2006;58:680-683.

23. Markowitz N, Quinn EL, Saravolatz KD. Trimethoprim-Sulfamethoxazole compared with vancomycin for the treatment of Staphylococcus aureus infections. Ann Int Med. 1992;117:390-398.

24. Szumowski JD, Choen DE, Kanaya F, et al. Treatment and outcomes of infections by methicillin-resistant Staphylococcus aureus at an ambulatory clinic. Antimicrob Agents Chemother. 2007;51:423-428.

25. Cleocin ${ }^{\circledR}$ [package insert]. New York, NY, USA: Pfizer Inc; 2007.

26. Dumitrescu O, Boisset S, Badrion C, et al. Effect of antibiotics on Staphylococcus aureus producing Panton-Valentine Leukocidin. Antimicrob Agents Chemother. 2007;51:1515-1519.

27. Siberry GK, Tekle T, Caroll K, et al. Failure of clindamycin treatment of methicillin-resistant Staphylococcus aureus expressing inducible clindamycin resistance in vitro. Clin Infect Dis. 2003;37:1257-1260.

28. Patel JB, Jevitt LA, Hageman J, et al. An association between reduced susceptibility to daptomycin and reduced susceptibility to vancomycin in Staphylococcus aureus. Clin Infect Dis. 2006a; 42:1652-1653.

29. Vibramycin ${ }^{\circledR}$ [package insert]. New York, NY, USA: Pfizer Inc; 2001.

30. Minocin ${ }^{\circledR}$ [package insert]. Philadelphia, PA, USA: Wyeth Pharmaceuticals; 2005.

31. Ruhe JJ, Monson T, Bradsher RW, et al. Use of long-acting tetracyclines for methicillin-resistant Staphylococcus aureus infections: case series and review of the literature. Clin Infect Dis. 2005;40(10):1429-1434.

32. Sumycin $^{\circledR}$ [package insert]. Spring Valley, NY, USA: Par Pharmaceuticals; . 2006.

33. Tenover FC, McDougal LK, Goering RV, et al. Characterization of a strain of community-associated methicillin-resistant Staphylococcus aureus widely disseminated in the United States. J Clin Microbiol. 2006;44(1):108-118.

34. Zyvox ${ }^{\circledR}$ [package insert]. New York, NY, USA: Pfizer Inc; 2008

35. Weigelt J, Itani K, Stevens D, et al. Linezolid versus vancomycin in treatment of complicated skin and soft tissue infections. Antimicrob Agents Chemother. 2005;171:388-416.

36. Tsiodras S, Gold HS, Sakoulas G, et al. Linezolid resistance in a clinical isolate of Staphylococcus aureus. Lancet. 2001;358:207-208.

37. Stevens DL, Ma Y, Salmi DB, McIndoo E, Wallace RJ, Bryant AE. Impact of antibiotics on expression of virulence-associated exotoxin genes in methicillin-sensitive and methicillin-resistant Staphylococcus aureus JID. 2007;195:202-211.

38. Strausbaugh LJ, Jacobson C, Sewell DL, et al. Antimicrobial therapy for methicillin-resistant Staphylococcus aureus colonization in residents and staff of a Veterans Affair nursing home care unit. Infect Control Hosp Epidemiol. 1992;13(3):151-159. 
39. Rifadin ${ }^{\circledR}$ [package insert]. Bridgewater, NJ, USA: Sanofi-aventis US LCC; 2007.

40. Stryjewski ME, Chambers HF. Skin and soft-tissue infections caused by community-acquired methicillin-resistant Staphylococcus aureus Clin Infect Dis. 2008;46:S368-S377.

41. Hooper DC. Mechanisms of quinolone resistance. Drug Resistance Updates. 1999;2:38-55.

42. Tenover FC, Moellering RC. The rationale for revising the clinical and laboratory standards institute vancomycin minimal inhibitory concentration interpretive criteria for Staphylococcus aureus. Clin Infect Dis. 2007;44:1208-1215.

43. Synercid ${ }^{\circledR}$ [package insert]. Bristol, TN, USA: Monarch Pharmaceuticals; 2003.

44. Saravolatz LD, Pawlak J, Johnson LB. Comparative activity of telavancin against isolates of community-associated methicillin-resistant Staphylococcus aureus. J Antimicrob Chemother. 2007;60(2):406-409.

45. Mendes RE, Sader HS, Deshpande L, et al. Antimicrobial activity of tigecycline against community-acquired methicillin-resistant Staphylocoous aureus isolates recovered from North America. Diagn Microbiol Infect Dis. 2008;60(4):433-436.

46. Nichols RL, Graham DR, Barriere SL, et al. Treatment of hospitalized patients with complicated gram-positive skin and skin structure infections: two randomized, multicentre studies of quinupristin/dalfopristin versus cefazolin, oxacillin or vancomycin. Synercid Skin and Skin Structure Infection Group. J Antimicrob Chemother. 1999;44(2): 263-273.

47. Moellering RC, Linden PK, Reinhardt J, et al. The efficacy and safety of quinupristin/dalfopristin for the treatment of infections caused by vancomycin-resistant Enterococcus faecium. Synercid Emergency-Use Study Group. J Antimicrob Chemother. 1999;44(2):251-261.

48. Cubicin ${ }^{\circledR}$ [package insert]. Lexington, MA, USA: Cubist Pharmaceuticals; 2007.

49. Johnson LB, Saeed S, Pawlak J, et al. Clinical and laboratory features of community-associated methicillin-resistant Staphylococcus aureus: is it really new? Infect Control Hosp Epidemiol. 2006;27(2):133-138.

50. Cui L, Tominaga E, Neoh HM, et al. Correlation between reduced daptomycin susceptibility and vancomycin resistance in vancomycinintermediate Staphylococcus aureus. Antimicrob Agents Chemother 2006;50:1079-1082.

51. Patel M, Waites KB, Moser SA, et al. Prevalence of inducible clindamycin resistance among community and hospital-associated Staphylococcus aureus isolates. J Clin Microbiol. 2006b; 44:2481-2482.

52. Sakoulas G, Alder J, Thauvin-Eliopoulos C, et al. Induction of daptomycin heterogeneous susceptibility in Staphylococcus aureus by exposure to vancomycin. Antimicrob Agents Chemother. 2006;50:1581-1585.

53. Pillai SK, Gold HS, Sakoulas G, et al. Daptomycin nonsusceptability in Staphylococcus aureus with reduced Vancomycin susceptibility is independent of alterations in MprF. Antimicrob Agents Chermother. 2007;51:2223-2226.

54. Arbeit RD, Maki D, Tally FP, et al. Daptomycin 98-01 and 99-01 Investigators. The safety and efficacy of daptomycin for the treatment of complicated skin and skin-structure infections. Clin Infect Dis. 2004;38(12):1673-1681.

55. Fowler VG Jr, Boucher HW, Corey GR, et al. Daptomycin versus standard therapy for bacteremia and endocarditis caused by Staphylococcus aureus. N Engl J Med. 2006;355(7):653-665.

56. Katz DE, Martone WJ. Community-phenotype-methicillin-resistant Staphylococcus aureus infections: a retrospective chart review of outcomes after treatment with daptomycin. Clin Ther. 2007;29(11):2440-2447.

57. Tygacil ${ }^{\mathbb{E}}$ [package insert]. Philadelphia, PA, USA: Wyeth Pharmaceuticals; 2007.

58. Breedt J, Teras J, Gardovskis J, et al. Tigecycline 305 c Study Group. Safety and efficacy of tigecycline in treatment of skin and skin structure infections: results of a double-blind phase 3 comparison study with vancomycin-aztreonam. Antimicrob Agents Chemother 2005;49(11):4658-4666.
59. Sacchidanand S, Penn RL, Embil JM, et al. Efficacy and safety of tigecycline monotherapy compared with vancomycin plus aztreonam in patients with complicated skin and skin structure infections: Results from a phase 3, randomized, double-blind trial. Int J Infect Dis. 2005; 9(5):251-261.

60. McAleese F, Murphy E, Babinchak T, et al. Use of ribotyping to retrospectively identify methicillin-resistant Staphylococcus aureus isolates from phase 3 clinical trials for tigecycline that are genotypically related to community-associated isolates. Antimicrob Agents Chemother. 2005;49(11):4521-4529.

61. Bailey J, Summers KM. Dalbavancin: a new lipoglycopeptide antibiotic. Am J Health Syst Pharm. 2008;65(7):599-610.

62. Seltzer E, Dorr MB, Goldstein BP, et al. Dalbavancin Skin and Soft-Tissue Infection Study Group. Once-weekly dalbavancin versus standard-of-care antimicrobial regimens for treatment of skin and softtissue infections. Clin Infect Dis. 2003;37(10):1298-1303.

63. Jauregui LE, Babazadeh S, Seltzer E, et al. Randomized, double-blind comparison of once-weekly dalbavancin versus twice-daily linezolid therapy for the treatment of complicated skin and skin structure infections. Clin Infect Dis. 2005;41(10):1407-1415.

64. Raad I, Darouiche R, Vazquez J, et al. Efficacy and safety of weekly dalbavancin therapy for catheter-related bloodstream infection caused by gram-positive pathogens. Clin Infect Dis. 2005;40(3): 374-380.

65. Goldstein EJ, Citron DM, Warren YA, et al. In vitro activities of dalbavancin and 12 other agents against 329 aerobic and anaerobic gram-positive isolates recovered from diabetic foot infections. Antimicrob Agents Chemother. 2006;50(8):2875-2879.

66. Attwood RJ, LaPlante KL. Telavancin: a novel lipoglycopeptide antimicrobial agent. Am J Health Syst Pharm. 2007;64(22):2335.

67. Stryjewski ME, Graham DR, Wilson SE, et al. Assessment of Telavancin in Complicated Skin and Skin-Structure Infections Study. Telavancin versus vancomycin for the treatment of complicated skin and skin-structure infections caused by gram-positive organisms. Clin Infect Dis. 2008;46(11):1683-1693.

68. Fowler VG Jr, Rude TH, Nelson CL, et al. Activity of telavancin against Staphylococcus aureus isolates carrying the Panton-Valentine leukocidin gene in the ATLAS studies [abstract 847]. In: Program and abstracts of the 17th European Congress of Clinical Microbiology and Infectious Diseases (Munich). 2007.

69. Poulakou G, Giamarellou H. Oritavancin: a new promising agent in the treatment of infections due to Gram-positive pathogens. Expert Opin Investig Drugs. 2008;17(2):225-243.

70. Giamarellou H, O'Riordan W, Harris H, et al. Phase 3 trial comparing 3-7 days of oritavancin vs 10-14 days of vancomycin/ cephalexin in the treatment of patients with complicated skin and skin structure infections (c) [abstract]. In: Program and abstracts of the 43rd Interscience Conference on Antimicrobial Agents and Chemotherapy (Chicago). Washington, DC: American Society for Microbiology. 2003.

71. Wasilewski M, Dish D, McGill J, et al. Equivalence of shorter course of therapy with oritavancin vs vancomycin/cephalexin in complicated skin and skin structure infections (c) [abstract UL-18]. In: Program and abstracts of the 41st Interscience Conference on Antimicrobial Agents and Chemotherapy (Chicago). Washington, DC: American Society for Microbiology. 2001.

72. Fluit AC, Schmitz FJ, Verhoef J, et al. SCCmec activity of AZD2563, a novel oxazolidinone, against European Gram-positive cocci. J Antimicrob Chemother. 2002;50:271-276.

73. McKee EE, Ferguson M, Bentley AT, et al. Inhibition of mammalian mitochondrial protein synthesis by oxazolidinones. Antimicrob Agent and Chemo. 2006;50(6):2042-2049.

74. Chung M, Antignac A, Kim C, et al. Comparative study of the susceptibilities of major epidemic clones of methicillin-resistant Staphylococcus aureus to oxacillin and to the new broad-sepctrum cephalosporin ceftobiprole. Antimicrob Agents Chemother. 2008;52(8): 2709-2717. 
75. Fritsche TR, Sader HS, Jones RN. Antimicrobial activity of ceftobiprole, a novel anti-methicillin-resistant Staphylococcus aureus cephalosporin, tested against contemporary pathogens: results from the SENTRY antimicrobial surveillance program (2005-2006). Diag Microb Infect Dis. 2008;61:86-95.

76. Sader HS, Fritsche TR, Jones RN. Antimicrobial activities of Ceftaroline and ME1036 tested against clinical strains of community-acquired methicillin-resistant Staphylococcus aureus. Antimicrob Agents Chemother. 2008;52(3):1153-1155.

77. Lo TS, Welch JM, Alonto AM, et al. A review of the carbapenems in clinical use and clinical trials. Recent Patents Anti-Infect Drug Disc. 2008;3(2):123-131.

78. Brady A, Loughlin R, Gilpin D, et al. In vitro activity of teatree oil against clinical skin isolates of methicillin-resistant and sensitive Staphylococcus aureus and coagulase-negative staphylococci growing planktonically and as biofilms. J Medical Microbiol. 2006;55:1375-1380.

79. Dryden MS, Dailly S, Crouch M. A randomized, controlled trial of tea tree topical preparations versus a standard topical regimen for the clearance of MRSA colonization. J Hosp Infect. 2004;56:283-286.

80. McMahon MA, Blair I, Moore J, et al. Habituation to sub-lethal concentrations of tea tree oil (Melaleuca alternifolia) is associated with reduced susceptibility to antibiotics in human pathogens. $J$ Antimicrob Chemother. 2007;59:125-127.

81. Han L, McDougal L, Gorwitz R, et al. High frequencies of clindamycin and tetracycline resistance in methicillin-resistant Staphylococcus aureus pulsed-field type USA300 isolates collected at a Boston ambulatory health center. J Clin Microbiol. 2007;45:1350-1352.

82. Diep BA, Chambers HF, Grabers CJ, et al. Emergence of multidrugresistant, community-associated, methicillin-resistant Staphylococcus aureus clone USA300 in men who have sex with men. Ann Intern Med. 2008;148(4):249-257.
83. Moran GJ, Krishnadasan A, Gorwitz RJ, et al. Methicillin-resistant Staphylococcus aureus infections among patients in the emergency department. N Engl J Med. 2006;355:666-674.

84. Stevens DL, Bisno AL, Chambers HF, et al. Practice guidelines for the diagnosis and management of skin and soft-tissue infections. Clin Infect Dis. 2005;41(10):1373-1406.

85. Abbott. Sterile vancomycin hydrochloride, USP ADD-Vantage ${ }^{\mathbb{R}}$ vials prescribing information. North Chicago, IL.1998.

86. Crum NF, Lee RU, Thornton SA, et al. Fifteen-year study of the changing epidemiology of methicillin-resistant Staphylococcus aureus. Am J Med. 2006;119(11):943-951.

87. Fridkin SK, Hageman JC, Morrison M, et al. Active Bacterial Core Surveillance Program of the Emerging Infections Program Network. Methicillin-resistant Staphylococcus aureus disease in three communities. N Engl J Med. 2005;352(14):1436-1444.

88. Huang H, Flynn NM, King JH, et al. Comparisons of communityassociated methicillin-resistant Staphylococcus aureus (MRSA) and hospital-associated MSRA infections in Sacramento, California. J Clin Microbiol. 2006;44(7):2423-2427.

89. King MD, Humphrey BJ, Wang YF, et al. Emergence of communityacquired methicillin-resistant Staphylococcus aureus USA300 clone as the predominant cause of skin and soft-tissue infections. Ann Intern Med. 2006;144(5):309-317.

90. Naimi TS, LeDell KH, Boxrud DJ, et al. Epidemiology and clonality of community-acquired methicillin-resistant Staphylococcus aureus in Minnesota, 1996-1998. Clin Infect Dis. 2001;33(7):990-996.

91. Tsuji BT, Rybak MJ, Cheung CM, et al. Community- and health careassociated methicillin-resistant Staphylococcus aureus: a comparison of molecular epidemiology and antimicrobial activities of various agents. Diagn Microbiol Infect Dis. 2007;58(1):41-47.
Infection and Drug Resistance

\section{Publish your work in this journal}

Infection and Drug Resistance is an international, peer-reviewed openaccess journal that focuses on the optimal treatment of infection (bacterial, fungal and viral) and the development and institution of preventive strategies to minimize the development and spread of resistance. The journal is specifically concerned with the epidemiology of antibiotic

\section{Dovepress}

resistance and the mechanisms of resistance development and diffusion in both hospitals and the community. The manuscript management system is completely online and includes a very quick and fair peer-review system, which is all easy to use. Visit http://www.dovepress.com/ testimonials.php to read real quotes from published authors. 